\title{
Access, demand, and utilization of childhood immunization services: A cross-sectional household survey in Western Area Urban district, Sierra Leone, 2019
}

\author{
Leora R Feldstein ${ }^{1,2}$, \\ Roberta Sutton ${ }^{3}$, Mohamed \\ F Jalloh ${ }^{1}$, Lauren Parmley ${ }^{3}$, \\ Maria Lahuerta ${ }^{3,4}$, Adewale \\ Akinjeji ${ }^{3}$, Anthony \\ Mansaray $^{3}$, Oliver Eleeza ${ }^{3}$, \\ Tom Sesay ${ }^{5}$, Shibani \\ Kulkarni ${ }^{1,6}$, Laura Conklin ${ }^{1}$, \\ Aaron S Wallace ${ }^{1}$ \\ ${ }^{1}$ Global Immunization Division \\ (GID), Centers for Disease Control \\ and Prevention, Atlanta, Georgia, \\ USA \\ ${ }^{2}$ Epidemic Intelligence Service, \\ Centers for Disease Control and \\ Prevention, Atlanta, Georgia, USA \\ ${ }^{3}$ ICAP at Columbia University, Mail- \\ man School of Public Health, New \\ York, New York, USA \\ ${ }^{4}$ Department of Epidemiology, \\ Mailman School of Public Health, \\ New York, New York, USA \\ ${ }^{5}$ Child Health/EPI Program, Sierra \\ Leone Ministry of Health and Sani- \\ tation, Freetown, Sierra Leone \\ ${ }^{6}$ Evaluation Fellow (Oak Ridge In- \\ stitute for Science and Education), \\ GID, Centers for Disease Control \\ and Prevention, Atlanta, Georgia, \\ USA
}

\section{Correspondence to:}

Leora Feldstein, PhD, MSc

1600 Clifton Road NE

Atlanta GA 30329

USA

nqw5@cdc.gov
Background Urban childhood immunization programs face unique challenges in access, utilization, and demand due to frequent population movement between and within localities, sprawling informal settlements, and population heterogeneity. We conducted a cross-sectional household survey in the Western Area Urban district, Sierra Leone, stratified by slums and non-slums as defined by the United Nations Development Program.

Methods Based on data from child vaccination cards, weighted vaccination coverage was estimated from 450 children aged 12-36 months (household response rate $=83 \%$ ). Interviews with 444 caregivers identified factors related to accessing routine immunization services. Factors associated with coverage in bivariate analyses were examined in multivariate models using backward stepwise procedure.

Results Coverage was similar in slums and non-slums for 3-doses of diphtheria-tetanus-pertussis-hepatitis B-Haemophilus influenzae type b (pentavalent) vaccine $(86 \%, 92 \%)$ and second dose of measles vaccine $(33 \%, 29 \%)$. In a multivariate logistic regression model, incomplete pentavalent vaccine coverage was associated with being second or later birth order (adjusted odds ratio $(\mathrm{aOR})=4.5$ (95\% confidence interval $(C I)=1.4-14.9)$, a household member not approving of childhood vaccinations ( $\mathrm{aOR}=7.55,95 \% \mathrm{CI}=1.52-37.38)$, self-reported delay of child receiving recommended vaccinations $(\mathrm{aOR}=4.8,95 \% \mathrm{CI}=1.0-22.1)$, and living in a household made of natural or rudimentary materials $(\mathrm{aOR}=3.5$, 95\% CI=1.2-10.6). Overall, the majority ( $>70 \%$ ) of caregivers reported occupation as petty trader and $<50 \%$ reported receiving vaccination information via preferred communication sources.

Conclusions Although vaccination coverage in slums was similar to non-slums, study findings support the need for targeted interventions to improve coverage, especially for the second dose of measles vaccine to avoid large scale measles outbreaks. Strategies should focus on educating household members via preferred communication channels regarding the importance of receiving childhood vaccinations on time for all offspring, not just the first born. Vaccination coverage could be further improved by increasing accessibility through innovative strategies such as increasing the number of vaccination days and modifying hours.

The Expanded Program on Immunization (EPI) was established by WHO in 1974 to ensure all children had access to routinely recommended vaccines that prevent morbidity and mortality from six diseases [1,2]: tuberculosis, polio, mea- 
sles, diphtheria, tetanus, and pertussis. Since 2008, there has been a global reduction in deaths due to vaccine-preventable diseases (VPDs) among children under the age of five. Nevertheless, according to the World Health Organization (WHO), in 2008 alone, there were more than 1.5 million deaths among this age group due to VPDs, $46 \%$ of whom lived in Africa [3]. Despite efforts to make vaccines available and accessible to all eligible children around the world, almost 20 million children were under- or unvaccinated in 2018 [3,4].

Sierra Leone established the national EPI in 1978 and the program now includes vaccines against five additional diseases: yellow fever, rotavirus, hepatitis B, Haemophilus influenzae type b, and pneumococcal disease [5]. From 1986-1990, national coverage of routine vaccinations (from WHO and UNICEF), including the third dose of diphtheria-tetanus-pertussis-containing vaccine (DTPcv), increased from $6 \%$ to $75 \%$ in Sierra Leone during the final phase of the Universal Child Immunization initiative [6]. Vaccine coverage declined, however, during the 1991-2002 country's civil conflict and the 2014-2015 Ebola Virus outbreak [7]. As of 2018, national routine coverage with three doses of DTPcv and the first dose of measles-containing vaccine (MCV1) were estimated to be $90 \%$ and $80 \%$, respectively [7]. Along with numerous health systems-related setbacks caused by the Ebola outbreak, suboptimal routine vaccination coverage remains a major public health concern in Sierra Leone. Despite reported improvements in coverage following the Ebola outbreak, the country has experienced multiple measles outbreaks, including one as recently as June 2018 [8]. To prevent measles outbreaks by achieving herd immunity within the population, it is estimated that coverage of at least $95 \%$ for two doses of MCV needs to be sustained [4].

Almost 15\% of Sierra Leone's population resides in Western Area Urban (WAU) district where the country's capital Freetown is located [9]. Compared to rural areas, urban areas like Freetown may be assumed to have higher uptake of essential health care services including immunization, given the greater geographic accessibility to health facilities and availability of diverse information sources and social networks. However, the opposite is often true [10]. Vaccination coverage in WAU from the Multiple Indicator Cluster Survey (MICS) (86\% for the third dose of DTPcr and 81\% for MCV1), was similar to the 2018 national coverage [11]. Urban immunization programs face unique challenges, such as frequent population movement between and within localities, sprawling of informal settlements, and heterogeneity of the population [12]. Informal settlements and slum communities within urban areas have populations with generally low socioeconomic status which may result in gaps and inequities in the uptake of health services, particularly for childhood immunizations [13]. To the best of our knowledge, no data were previously available to determine if coverage varied by slum and non-slum areas of WAU district, Sierra Leone as of 2017. Slums were defined by the United Nations Development Program as having: lack of basic services, sub-standard housing or illegal and inadequate building structures, overcrowding and high density, unhealthy living conditions and hazardous locations, insecure tenure, irregular and informal settlements [14].

Our primary research question of interest was to understand the relationship between a child's residence (slum and non-slum) and their vaccination status. We conducted a cross-sectional household survey in WAU district, stratified by designated slum and non-slums to estimate vaccination coverage among children 12-36 months old and identify factors contributing to underutilization of, and barriers to accessing routine immunization services. The objective was to provide actionable data to guide the Sierra Leone Ministry of Health and Sanitation (MoHS) to improve access, demand, and utilization of immunization services by tailoring and strengthening immunization services in Freetown and other similar urban settings in the country.

\section{METHODS}

\section{Study setting and population}

In WAU district, routine childhood vaccinations are administered by trained health care workers at fixed sites within health facilities, as well as through outreach visits, and designated routine immunization days in a central community location. The current childhood vaccination schedule in Sierra Leone follows the recommended WHO vaccination schedule. It includes a birth dose of bacillus Calmette-Guérin (BCG) and oral polio vaccine (OPV); doses of OPV, diphtheria-tetanus-pertussis-hepatitis B-Haemophilus influenzae type b (pentavalent) vaccine, pneumococcal, and rotavirus vaccine at 6 weeks, 10 weeks, and 14 weeks of age; yellow fever vaccine and MCV1 at 9 months; and MCV2 at 
15 months of age. Pneumococcal vaccine, rotavirus vaccine, and MCV2 were all introduced into the national schedule within the past eight years (2011, 2012, and 2015, respectively) [5]. As a result of MCV2 introduction, the Sierra Leone MoHS and global partners have placed a renewed emphasis on strengthening child health interventions during the second year of life.

\section{Study design}

A household survey was conducted with eligible caregivers of children aged 12-36 months in WAU district, Sierra Leone from March 4 to April 8, 2019. Two-stage probability sampling methodology was used to randomly select 58 enumeration areas (EA) from the 2015 Sierra Leone Census, stratified by setting (29 slum EAs and 29 non-slum EAs according to the designated definition), and simple random sampling was used to select 10 eligible households (physical structures or dwellings) per EA from a newly created EA household line listing (Appendix S1 in the Online Supplementary Document). All eligible children within a household were selected for inclusion in the study, and their primary caregivers were selected for interviews. The data collection teams visited the selected EAs at varying times of the day, including mornings, afternoons, and evenings to increase the chances of locating eligible participants on the enumerated list. If a caregiver was not present, data collectors returned to the household up to three times at another time of the day or on a different day. Households with unreachable caregivers were not replaced or substituted. Individuals were eligible to participate if they were aged 15 years and older, living in residential households in the selected EAs for the past 6 months, and were primary caregivers of children aged 12-36 months.

\section{Data collection}

Caregivers of children aged 12-36 months were interviewed near their households, using a tablet-based respondent questionnaire. Key topics included knowledge of available immunization services, access to information and services, barriers and facilitators to vaccination-seeking behavior including attitudes toward vaccines, and influencers at household, community and societal levels. Data from the child's vaccination card was abstracted and entered into tablets to ascertain the immunization status of the child. Caregiver recall was also collected those children without vaccination cards.

\section{Ethics approval and consent}

The survey was approved by Columbia University Medical Center's Institutional review board, the Centers for Disease Control and Prevention (CDC) Office of the Associate Director for Science, Center for Global Health, and Sierra Leone's MoHS institutional review board. Written or thumb-printed (for illiterate participants) informed consent was obtained from participants in either English or Krio. If the caregiver was $<18$ years, the parent of the caregiver was asked to consent, and minor assent was obtained. Caregivers were excluded from the survey if they were unable or unwilling to provide consent. Participation was voluntary, and the objectives, length of survey, and risks/benefits of participation were explained to individuals prior to enrollment.

\section{Statistical analysis}

Descriptive statistics were used to summarize demographic data, as well as access, demand, and utilization of childhood vaccinations in slum and non-slums of WAU. From collected vaccination card data, estimations of vaccination coverage and the corresponding 95\% confidence intervals of point estimates were made using complex survey procedures that accounted for the two-stage cluster design and sampling weights [15]. A timeliness analysis to assess whether children had received all of their vaccinations within 24 months of age was conducted among all children who were age-eligible (15 months or older) for MCV2 - the final vaccine dose in the national childhood immunization schedule. $\chi^{2}$ tests were used to examine differences between slum and non-slums in uptake of various scheduled vaccines, access-related determinants, and attitudes toward vaccination. A multivariable logistic regression model was fit to the data to examine the odds of incomplete pentavalent vaccination status among children of caregivers who resided in slum communities compared to those residing in non-slum communities. Variables considered for inclusion in the model were significantly associated $(P<0.05)$ with either geographic location (slum vs non-slum) or complete vaccination coverage of pentavalent vaccine in the bivariate analysis. When using a manual backward stepwise procedure, these variables were retained in the multivariate analysis if they remained significant at the 0.05 level. All analyses were completed in STATA 14 (StataCorp, College Station TX, USA). 


\section{RESULTS}

\section{Enrollment}

A total of 4275 structures comprising 7869 households were enumerated in the 58 randomly selected EAs, of which 1268 households were determined to be eligible for inclusion in the study. At least 80\% of households in each EA provided household listing information. Data collection teams visited 535 households selected from a created list of eligible households; 277 (52\%) were in slums and 258 (48\%) were in non-slums (Figure 1). Questionnaires were completed from 443 households with an overall response rate of $83 \%$. Eligible caregivers, infants, or entire households who had moved out of the area since enumeration (72\%) comprised the majority of the non-responders. Of the 443 completed households, 454 caregivers of 470 children aged 12-36 months were interviewed. There were 10 children and their caregivers excluded from analyses due to being age-ineligible (Table 1). Therefore, the final analysis included data from 444 caregivers and 460 children (240 children from 236 households in slums and 220 children from 207 households in non-slums).

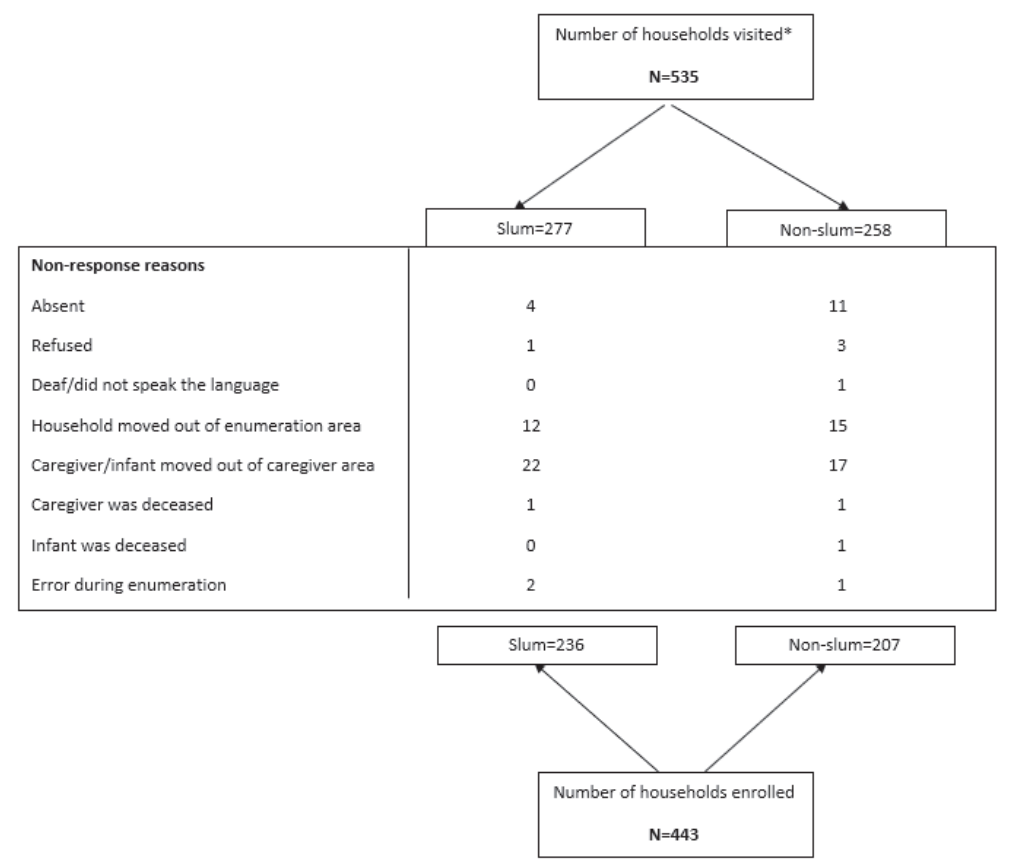

Figure 1. Households included in the analysis and reasons for exclusion, (unweighted), household survey, WAU district, Sierra Leone, 2019. *Visited households are defined as all eligible households (physical structures or dwellings) that were visited by data collection teams up to three times. WAU - Western Area Urban

Table 1. Caregivers and eligible children included in the analysis by slum and non-slum areas, (unweighted), household survey, Western Area Urban district, Sierra Leone, 2019

\begin{tabular}{lccc} 
& SLUM, N (\%) & Nlon-SLUM, N (\%) & Total, II \\
Number of caregivers interviewed & $240(53)$ & $214(47)$ & 454 \\
\hline First enrolled caregiver within household & $236(53)$ & $207(47)$ & 443 \\
\hline Second enrolled caregiver within household & $4(36)$ & $7(66)$ & 11 \\
\hline Number of caregivers included in analysis* & $234(53)$ & $210(47)$ & 444 \\
\hline Number of participating children & $246(52)$ & $224(48)$ & 470 \\
\hline First enrolled child within household & $236(53)$ & $207(47)$ & 443 \\
\hline Second enrolled child within household & $6(38)$ & $10(62)$ & 16 \\
\hline Third enrolled child within household & $4(36)$ & $7(66)$ & 11 \\
\hline Number of eligible children enrolled* & $240(52)$ & $220(48)$ & 460 \\
\hline
\end{tabular}

WAU - Western Area Urban

* 10 children and caregivers were enrolled and interviewed but excluded during the analysis phase because the children were not between 12-36 months of age either at the time of enumeration or at the time of interview. 


\section{Demographic characteristics of children and caregivers}

The median age of participating children was 24 months in slums and 25 months in non-slums (Table 2). Forty-six percent $(n=109)$ and $53 \%(n=117)$ of these children were female in slum and non-slums, respectively. The median birth order of participating children was second for both slum and non-slums, and the majority of participating caregivers were mothers ( $90 \%$ and $89 \%$, respectively). The median maternal age was 26 years in both areas (Table 2). The majority of mothers in slum and non-slums were married $(67 \%(n=156)$ and $64 \%(n=134)$, respectively), Muslim $(78 \%(n=182)$ and $62 \%(n=119)$, respectively), and considered themselves to be petty traders (67\% ( $n=156)$ and $54 \%(n=113)$, respectively). A smaller proportion of mothers in slums reported completing junior secondary school or higher compared to mothers in non-slums (45\% and 60\%, respectively).

\section{Household characteristics}

Although household size ranged from 1-23 individuals, median size was five in both slum and nonslums (Table 2). Most households $(82 \%(n=195)$ in slums and $74 \%(n=153)$ in non-slums) had access to piped or dug well water but did not have these potable water sources in their homes or on their land ( $72 \%(\mathrm{n}=143$ ] in slums and 74\% ( $\mathrm{n}=122)$ in non-slums) (Table S1 in the Online Supplementary Document). Almost a quarter $(24 \%, \mathrm{n}=56)$ of homes in slums used a bucket, hanging toilet or plastic bag as toilet facilities, compared to $5 \%(\mathrm{n}=10)$ of households in non-slums. A greater proportion of households in non-slums had electricity, a radio, television, mobile phone, and refrigerator than households in slums; 43\% ( $n=88)$ and 29\% ( $n=69)$, respectively. A greater proportion of non-slums also had rudimentary or finished walls, floors, and roof compared to households in slums (94\% $(n=207)$ and 89\% $(\mathrm{n}=213)$, respectively).

\section{Access to and utilization of routine immunization}

Caregiver access and utilization of routine immunization did not differ significantly between slum and non-slums. Caregivers in both areas reported similar travel time from their home to vaccination sites and similar wait times at vaccination sites (Table S2 in the Online Supplementary Document). More than one quarter (34\%-40\%) of all caregivers reported that transportation time to vaccination sites was "too much time". When asked about preferred location for an additional vaccination site, the majority of caregivers reported that they would like a site close to home (88\%-90\%) compared to close to work or the market. In both areas, $79 \%$ of caregivers reported that wait time at vaccination sites was $\geq 30$ minutes and $14 \%-22 \%$ of caregivers viewed this as "too much time". Half of all caregivers (50\%) reported having to pay health care workers for routine immunization services, even though services are supposed to be free of charge. One in ten caregivers reported attending a vaccination site but having to return home without their child being vaccinated. Among caregivers returning home without getting their children vaccinated, the three main reasons reported for missed opportunities for vaccination were: "not enough children to open a vaccination vial", "vaccines were not available", and "it was not a scheduled vaccination day".

Very few caregivers self-reported refusing recommended vaccinations for their child (2\%-6\%); however, $36 \%-37 \%$ of caregivers self-reported delaying vaccination for their child (Table S2 in the Online Supplementary Document). Of the 17 caregivers who self-reported vaccine refusal, 10 cited fear of vaccination side effects (Table S3 in the Online Supplementary Document). Of the 163 caregivers who self-reported vaccine delay, the top three reasons were: lack of time to take child, child or caregiver were sick, and fear of vaccination side effects.

\section{Current and preferred sources of information about vaccines}

Sixty-two percent of caregivers in slums and $75 \%$ of caregivers in non-slums received information about childhood vaccinations from health facilities. However, only $43 \%$ of caregivers in slums and $47 \%$ of caregivers in non-slums reported that health facilities were their preferred source of information (data not shown). Caregivers in both areas reported that household visits, radio programming, and community-based events were their preferred modes of communication relating to childhood vaccination.

\section{Perceptions of childhood vaccination}

Perceptions of childhood vaccination were similar among caregivers in slum and non-slums. A high proportion of caregivers ( $\geq 90 \%$ ) in both slum and non-slums reported that they believe vaccines are good for their children, are safe, and protect their children against diseases (Table S4 in the Online Supplementa- 
Table 2. Child, caregiver, and household characteristics comparing slum to non-slum areas (unweighted), household survey, Western Area Urban district, Sierra Leone, 2019

\begin{tabular}{|c|c|c|c|c|}
\hline \multirow[b]{2}{*}{ Child characteristics } & \multicolumn{2}{|c|}{ Slum $(n=240)$} & \multicolumn{2}{|c|}{ Non-slum $(n=220)$} \\
\hline & n or (median) & (Range) or $\%$ & n or (median) & (Range) or \% \\
\hline Median age of child in months* & $(24)$ & $(13-41)$ & $(25)$ & $(12-39]$ \\
\hline Median birth order & $(2)$ & $(1-10)$ & $(2)$ & $(1-8]$ \\
\hline First birth order & 63 & $47 \%$ & 71 & $53 \%$ \\
\hline Sex (female) & 109 & 46 & 117 & 53 \\
\hline \multirow[b]{2}{*}{ Caregiver/parent characteristics } & \multicolumn{2}{|c|}{ Slum $(n=234)$} & \multicolumn{2}{|c|}{ Non-slum $(n=210)$} \\
\hline & n or (median) & (Range) or \% & n or (median) & (Range) or $\%$ \\
\hline \multicolumn{5}{|l|}{ Caregiver (respondent) type: } \\
\hline Mother & 210 & 90 & 186 & 89 \\
\hline Father & 4 & 2 & 0 & 0 \\
\hline Grandmother & 14 & 6 & 17 & 8 \\
\hline Grandfather & 0 & 0 & 1 & $<1$ \\
\hline Other family member $\dagger$ & 5 & 2 & 6 & 3 \\
\hline Median maternal age & $(26)$ & $(18-46)$ & $(26)$ & $(17-48]$ \\
\hline Mother no longer alive & 0 & 0 & 1 & $<1$ \\
\hline \multicolumn{5}{|l|}{ Maternal marital status: } \\
\hline Married & 156 & 67 & 134 & 64 \\
\hline Living with partner & 39 & 17 & 24 & 11 \\
\hline Divorced/separated or widowed & 7 & 3 & 6 & 2 \\
\hline Never married/never lived with partner & 31 & 13 & 45 & 22 \\
\hline \multicolumn{5}{|l|}{ Maternal education status: } \\
\hline Mother never attended school & 73 & 32 & 35 & 17 \\
\hline Mother attended some or completed primary school & 55 & 24 & 83 & 23 \\
\hline Mother completed junior secondary school or higher & 103 & 45 & 126 & 60 \\
\hline \multicolumn{5}{|l|}{ Paternal education status: } \\
\hline Father never attended school & 44 & 21 & 32 & 16 \\
\hline Father attended some or completed primary school & 27 & 13 & 16 & 8 \\
\hline Father completed junior secondary school or higher & 136 & 66 & 146 & 75 \\
\hline \multicolumn{5}{|l|}{ Maternal religion: } \\
\hline Christian & 50 & 21 & 80 & 38 \\
\hline Muslim & 182 & 78 & 119 & 62 \\
\hline \multicolumn{5}{|l|}{ Paternal religion: } \\
\hline Christian & 53 & 23 & 58 & 28 \\
\hline Muslim & 176 & 77 & 150 & 72 \\
\hline \multicolumn{5}{|l|}{ Maternal employment: } \\
\hline Petty trader & 156 & 67 & 113 & 54 \\
\hline Private business owner & 14 & 6 & 25 & 12 \\
\hline Unemployed & 27 & 12 & 43 & 21 \\
\hline Student & 8 & 3 & 12 & 6 \\
\hline Medical or health professional & 2 & 1 & 5 & 2 \\
\hline Other (laborer, teacher, government or NGO employee) $\ddagger$ & 26 & 12 & 11 & 5 \\
\hline \multicolumn{5}{|l|}{ Paternal employment: } \\
\hline Petty trader & 29 & 13 & 20 & 10 \\
\hline Laborer & 74 & 32 & 54 & 26 \\
\hline Private business owner & 40 & 17 & 37 & 18 \\
\hline Government employee & 18 & 8 & 26 & 12 \\
\hline Public transportation or Okada/Keke driver & 22 & 10 & 19 & 9 \\
\hline Unemployed & 5 & 2 & 12 & 6 \\
\hline NGO employee & 5 & 2 & 9 & 4 \\
\hline Teacher & 3 & 1 & 7 & 3 \\
\hline \multirow[t]{2}{*}{ Other (farmer, medical professional, solider, student) $\neq$} & 33 & 14 & 25 & 12 \\
\hline & \multicolumn{2}{|c|}{ Slum $(n=236)$} & \multicolumn{2}{|c|}{ Non-slum $(n=207)$} \\
\hline Household level characteristics & $\mathrm{n}$ or (median) & (Range) or \% & n or (median) & (Range) or \% \\
\hline Median household size & $(5)$ & $(2-23)$ & $(5)$ & $(1-20]$ \\
\hline Median number of living children in household & $(2)$ & $(1-8)$ & $(2)$ & $(1-6]$ \\
\hline
\end{tabular}

NGO - non-governmental organization

*Age at time of enumeration, calculated from date of birth on the vaccination card. If vaccination card was unavailable, it was calculated from date of birth based on caregiver recall.

$\dagger$ Other family members include: aunt, cousin, niece, nephew, or sibling.

¥Categories with $\leq 2 \%$ were grouped into "Other". 
ry Document). When caregivers were asked whether they would encourage others to get their children vaccinated, 67\% in slums and 73\% in non-slums responded, "very much." Less than $80 \%$ of caregivers in both areas reported that parents and trusted leaders in the community "very much" approved and valued childhood vaccinations.

\section{Vaccination coverage}

Vaccination card retention at the time of interview was similar in slum and non-slums (75\% and 76\%, respectively) (Table 3). Using vaccination card data only, BCG vaccination coverage was high in both areas ( $\geq 98 \%)$. Overall, pentavalent vaccination coverage was similar between slum and non-slums; $97 \%$ for the first dose, 91\% for two doses, and 86\% for all three doses in slums and 96\% for the first dose, 94\% for two doses, and $92 \%$ for all three doses in non-slums. Similar to pentavalent vaccine coverage, there was an observed drop in coverage between the first and second measles doses; coverage was similar in slums and non-slums, with coverage for MCV2 (32\%-33\%) lower than coverage for MCV1 (75\%-77\%).

Table 3. Vaccination coverage of children ages 12-36 mo and characteristics comparing slum to non-slum areas (weighted), household survey, Western Area Urban district, Sierra Leone, 2019*

\begin{tabular}{|c|c|c|c|c|c|c|}
\hline \multirow[t]{2}{*}{ Vaceination coverage } & \multicolumn{2}{|c|}{ Stum $(N=238 t)$} & \multicolumn{2}{|c|}{ Non-sLum $(\mathrm{N}=220)$} & \multicolumn{2}{|c|}{ TotAl $(n=458)$} \\
\hline & $\%$ or (mean) & $95 \%$ CI & $\%$ or (mean) & $95 \%$ CI & $\%$ or (mean) & $95 \% \mathrm{CI}$ \\
\hline Mean age of most recent vaccination in months (recall) & $(11)$ & $11-12$ & (11) & $11-12$ & (11) & $11-12$ \\
\hline \multicolumn{7}{|l|}{ Owns vaccination card: } \\
\hline Yes, available & 75 & $69-81$ & 76 & $70-80$ & 76 & $71-80$ \\
\hline Yes, not seen & 19 & $15-25$ & 17 & $13-22$ & 17 & $14-22$ \\
\hline No & 6 & $3-10$ & 7 & $3-15$ & 7 & $4-14$ \\
\hline Vaccination coverage by card & \multicolumn{2}{|c|}{$\mathrm{n}=180$} & \multicolumn{2}{|c|}{$\mathrm{n}=170$} & \multicolumn{2}{|c|}{$\mathrm{n}=350$} \\
\hline BCG vaccination & 98 & $94-99$ & 100 & $98-100$ & 99 & $98-100$ \\
\hline Pental & 97 & $94-99$ & 96 & $83-100$ & 96 & $86-99$ \\
\hline Received two doses of penta & 91 & $85-95$ & 94 & $84-98$ & 94 & $86-97$ \\
\hline Received all three penta doses & 86 & $80-91$ & 92 & $83-97$ & 91 & $84-96$ \\
\hline MCV1 & 75 & $66-83$ & 79 & $66-86$ & 77 & $68-85$ \\
\hline MCV2 & 33 & $25-42$ & 32 & $21-46$ & 32 & $22-44$ \\
\hline Received BCG, all penta doses and 2 measles doses $\ddagger$ & 33 & $25-42$ & 29 & $19-42$ & 29 & $20-40$ \\
\hline $\begin{array}{l}\text { Received BCG, all penta doses and } 2 \text { measles doses by } 24 \\
\text { months\& }\end{array}$ & 22 & $16-30$ & 20 & $14-29$ & 20 & $15-28$ \\
\hline No vaccinations & 1 & $1-5$ & 0 & - & $<1$ & $<1-1$ \\
\hline Received all recommended vaccinations $\ddagger$ (recall) & 54 & $43-63$ & 53 & $41-64$ & 53 & $43-62$ \\
\hline
\end{tabular}

CI - confidence interval, BCG - Bacillus Calmette-Guérin; Penta - pentavalent vaccine (diphtheria-tetanus-pertussis-hepatitis B-Haemophilus influenzae type b), MCV1 - measles-containing vaccine, $1^{\text {st }}$ dose; MCV2 - measles-containing vaccine, $2^{\text {nd }}$ dose

* No significant differences at $P<0.05$ level

$†$ Missing data from two participants.

₹All recommended vaccines include BCG, Pental-3, MCV1-2, and 4 doses of oral polio vaccine.

§Only children $\geq 15$ months were included in the analysis.

According to caregiver recall, 54\% of children in slums and 53\% of children in non-slums received all recommended vaccines in the national routine schedule; however, according to vaccination card data, only $33 \%$ of children in slums and 29\% of children in non-slums received BCG, three doses of pentavalent, and two doses of measles vaccine. Of the caregivers who reported that their child received all recommended vaccines, only 8\% (95\% CI=3\%-18\%) had vaccination cards with documented receipt of MCV2. In comparison, 60\% (95\% CI=44\%-74\%) received $\mathrm{MCV1}$, and 86\% (95\% CI $=74 \%-93 \%)$ received the third dose of pentavalent vaccine (data not shown). Less than one quarter of all age-eligible children received these doses on time (by 24 months of age) (Table 3). Among children with vaccination cards $(n=350)$, $1 \%$ of children in slums and $0 \%$ of children in non-slums had never been vaccinated. Similar trends in vaccination coverage, by card and recall, among the 12 to 23 month-old birth cohort were observed (Table S5 in the Online Supplementary Document).

\section{Factors associated with vaccination coverage}

In bivariate analyses, failure to complete the pentavalent vaccination series (from vaccination card only) was significantly associated with second or higher birth order of the child, paternal education of primary school or less, living in a house without a flush or pour toilet, and living in a house with natural floor, 
roof, and wall materials (Table 4). Failure to complete the pentavalent vaccination series was significantly higher among children with caregivers who knew a child in their family or community with vaccine side effects in the last 12 months and those who self-reported delaying recommended vaccinations for their children (Table 5). Children who had not received three doses of pentavalent vaccine had caregivers who less frequently perceived that their spouses and household members "very much" approved of childhood vaccination and had caregivers who less frequently reported being confident in their ability to take their child for vaccination visits, $(P<0.01$ and $P=0.02$, respectively) (S5 Table). Children were also less likely to have received three doses of pentavalent vaccine series if their caregivers less frequently perceived that they lived in a community where people valued childhood vaccination and approved of childhood vaccination ( $P=0.03$ and $P=0.01$, respectively).

Table 4. Demographic and socioeconomic factors associated with receiving three doses of pentavalent vaccine among children who had a vaccination card at the time of interview* (weighted), household survey, WAU district, Sierra Leone, 2019

\begin{tabular}{|c|c|c|c|}
\hline & \multicolumn{2}{|c|}{ ALI threE PENTAVALENT VACCINE dOSES } & \multirow[t]{2}{*}{$P_{\text {-value }}$} \\
\hline & $\%$ & $95 \%$ CI & \\
\hline \multicolumn{4}{|l|}{ Urban setting: } \\
\hline Slum & 86 & $80-91$ & \multirow{2}{*}{0.18} \\
\hline Non-slum & 92 & $83-97$ & \\
\hline \multicolumn{4}{|l|}{ Gender of child: } \\
\hline Female & 94 & $83-98$ & \multirow{2}{*}{0.24} \\
\hline Male & 88 & $79-94$ & \\
\hline \multicolumn{4}{|l|}{ Maternal education level: } \\
\hline Never attended school & 89 & $73-96$ & \multirow{3}{*}{0.28} \\
\hline Attended some or completed primary school & 87 & $72-94$ & \\
\hline Completed junior secondary school or higher & 94 & $83-98$ & \\
\hline \multicolumn{4}{|l|}{ Paternal education level } \\
\hline Never attended school & 79 & $58-91$ & \multirow{3}{*}{0.03} \\
\hline Attended some or completed primary school & 95 & $87-98$ & \\
\hline Completed junior secondary school or higher & 94 & $85-98$ & \\
\hline \multicolumn{4}{|l|}{ Maternal religion: } \\
\hline Christian & 95 & $86-98$ & \multirow{2}{*}{0.34} \\
\hline Muslim & 90 & $79-95$ & \\
\hline \multicolumn{4}{|l|}{ Paternal religion: } \\
\hline Christian & 95 & $84-99$ & \multirow{2}{*}{0.33} \\
\hline Muslim & 90 & $81-95$ & \\
\hline \multicolumn{4}{|l|}{ Child birth order: } \\
\hline $1^{\text {st }}$ born & 98 & $95-99$ & \multirow{2}{*}{$<0.001$} \\
\hline$\geq 2^{\text {nd }}$ born & 88 & $77-94$ & \\
\hline \multicolumn{4}{|l|}{ Maternal marital status: } \\
\hline Married or living together & 90 & $80-95$ & \multirow{3}{*}{0.02} \\
\hline Divorced, separated or widowed & 94 & $61-99$ & \\
\hline Never married or lived together & 98 & $93-100$ & \\
\hline \multicolumn{4}{|l|}{ Type of toilet: } \\
\hline Flush or pour flush toilet & 98 & $95-99$ & \multirow{2}{*}{0.002} \\
\hline Pit Latrine, bucket, hanging toilet or plastic bag & 88 & $77-94$ & \\
\hline \multicolumn{4}{|c|}{ Household amenities composite variable (electricity, mobile phone, radio, television and refrigerator): } \\
\hline Has household amenities & 92 & $77-97$ & \multirow{2}{*}{0.93} \\
\hline Does not have household amenities & 91 & $85-95$ & \\
\hline \multicolumn{4}{|l|}{ Main material of house (floor, roof and walls): } \\
\hline Natural materials & 68 & $28-92$ & \multirow{2}{*}{0.01} \\
\hline Rudimentary or finished materials & 94 & $91-96$ & \\
\hline
\end{tabular}

WAU - Western Area Urban, CI - confidence interval

$* \mathrm{n}=350$ children $12-36$ months with vaccination card

Children who were age-eligible but had incomplete measles vaccination were more likely to have a mother and father who reported being Muslim; incomplete coverage was 66\% (95\% CI=53\%-78\%) among children with Muslim mothers compared to 47\%, 95\% CI=30\%-64\%) among Christian mothers and 64\% (95\% CI=50\%-76\%) among children with Muslim fathers compared to 42\%, 95\% CI=26\%-60\%) among Christian fathers (data not shown). Children with incomplete measles vaccination were also more 
likely to live in a house without amenities including electricity, a television, radio, mobile phone, refrigerator $(70 \%, 95 \% \mathrm{CI}=52 \%-83 \%)$ compared to $43 \%, 95 \% \mathrm{CI}=33 \%-55 \%$ (data not shown). Additionally, children whose caregivers delayed their vaccination were more likely to have incomplete measles vaccination coverage (34\%, 95\% CI =23\%-47\%) compared to $11 \%$ (5\%-22\%) (data not shown).

Table 5. Caregiver characteristics, perceptions, and decisions associated with receiving three doses of pentavalent vaccine among children who had a vaccination card at the time of interview* (weighted), household survey, WAU district, Sierra Leone, 2019

\begin{tabular}{|c|c|c|}
\hline & \multicolumn{2}{|c|}{ ALL threE PENTAVALENT VACCINE DOSES } \\
\hline & $\%$ & $95 \% \mathrm{Cl}$ \\
\hline \multicolumn{3}{|c|}{ Transportation time from home to vaccination site: } \\
\hline$<30 \mathrm{~min}$ & 92 & $83-97$ \\
\hline $30 \mathrm{~min}-1 \mathrm{~h}$ & 92 & $82-97$ \\
\hline$>1 \mathrm{~h}$ & 93 & $68-99$ \\
\hline \multicolumn{3}{|c|}{ Perception of time to reach usual vaccination site } \\
\hline About right & 94 & $86-98$ \\
\hline A short time & 91 & $83-95$ \\
\hline Too much time & 93 & $77-98$ \\
\hline \multicolumn{3}{|c|}{ Waiting time at vaccination site: } \\
\hline$<30 \mathrm{~min}$ & 82 & $57-94$ \\
\hline $30 \mathrm{~min}-1 \mathrm{~h}$ & 96 & $91-98$ \\
\hline$>1 \mathrm{~h}$ & 94 & $85-98$ \\
\hline \multicolumn{3}{|c|}{ Perception of wait time at vaccination site: } \\
\hline About right & 95 & $90-98$ \\
\hline A short time & 89 & $79-95$ \\
\hline Too much time & 89 & $67-97$ \\
\hline \multicolumn{3}{|c|}{ Payment to health care worker: } \\
\hline Nothing & 95 & $87-98$ \\
\hline 1000-5000 Leones & 92 & $85-96$ \\
\hline$\geq 6000$ Leones & 90 & $75-96$ \\
\hline \multicolumn{3}{|c|}{ Knowledge of child in family or community with vaccine side effects within last $12 \mathrm{mo}$ : } \\
\hline Yes & 70 & $37-91$ \\
\hline No & 93 & $87-96$ \\
\hline \multicolumn{3}{|c|}{ Self-reported refusal of recommended vaccination: } \\
\hline Yes & 75 & $39-94$ \\
\hline No & 93 & $87-96$ \\
\hline \multicolumn{3}{|c|}{ Self-reported delays in receiving recommended vaccination: } \\
\hline Yes & 81 & 63-92 \\
\hline No & 97 & $92-99$ \\
\hline
\end{tabular}

WAU - Western Area Urban, CI - confidence interval

$* \mathrm{n}=350$ children $12-36$ months with vaccination card.

In a multivariate analysis, the following covariates were most closely associated with incomplete pentavalent vaccination series: being born second or later (adjusted odds ratio $(a O R)=4.5,95 \% C I=1.4-14.9$ ), living in a household where a spouse, partner or household member does not approve of childhood vaccinations ( $\mathrm{aOR}=7.55,95 \% \mathrm{CI}=1.52-37.38)$, caregiver self-reporting delay of child receiving recommended vaccinations ( $\mathrm{aOR}=4.8,95 \% \mathrm{CI}=1.0-22.1)$, and living in a household made of natural or rudimentary materials (aOR=3.5, 95\% CI=1.2-10.6) (Table 6).

Table 6. Logistic regression model examining factors associated with incomplete pentavalent vaccine coverage $(\mathrm{n}=41)$ among children ages 12-36 months living in Western Area Urban district, Sierra Leone (weighted), household survey, 2019

\begin{tabular}{lccc} 
DID NOT REGEIVE ALI THREE DOSES OF PENTAVALENT VACGINE* & ODDS RATIO & 95\% CONFIDENGE INTERVAL & P-VALUE $^{*}$ \\
Living in a slum enumeration area & 1.8 & $0.70-4.8$ & 0.21 \\
\hline Child birth order $\left(1^{\text {st }}\right.$ vs $\left.\geq 2^{\text {nd }}\right)$ & 4.5 & $1.4-14.9$ & 0.01 \\
\hline Caregiver perceives that household member does not approve of vaccination & 8.7 & $2.2-34.2$ & 0.002 \\
\hline Self-reported delays in receiving recommended vaccination & 4.8 & $1.02-22.1$ & 0.05 \\
\hline Main materials of household (natural vs rudimentary or finished) & 3.5 & $1.2-10.6$ & 0.03 \\
\hline
\end{tabular}

*From vaccination card data only. 


\section{DISCUSSION}

Although we did not find any differences in vaccination coverage between slum and non-slums in a large urban area (WAU district) in Sierra Leone, our findings show that overall, almost 1 in 4 children had not received MCV1 and only 1 in 3 children received MCV2 vaccination. Based on the results of this survey, barriers to accessing and utilizing routine immunization services in both areas fell into four categories: 1) sociodemographic characteristics of the family, 2) caregiver perceptions of family and community beliefs, attitudes, and behaviors toward vaccination, 3) vaccination session scheduling, and 4) facility-based experiences and missed opportunities for vaccination. Of potential barriers identified, factors most closely associated with low vaccination coverage in multivariate analysis were a child being born second or later, caregivers perceived lack of support for vaccination from their spouse/partner or other household members, self-reported delay of child receiving recommended vaccinations, and living in a household made of natural or rudimentary materials.

Vaccination coverage estimates from this study for the third dose of pentavalent vaccine and MCV1 are consistent with recent estimates from other assessments in WAU district $[7,11]$. Findings from prior studies in sub-Saharan Africa aimed to identify predictors of vaccination coverage in urban areas and found the following: low or no maternal education level, low socioeconomic status, time constraints, past behaviors of delaying vaccination, and negative perceptions of vaccination were consistently associated with lower coverage across multiple studies [16-21]. In our study, the proportion of children who received all vaccines on time (within 24 months of age) is also low (20\%) and delaying vaccination can increase the risk of child deaths due to a VPD. In comparison, two studies in urban areas of sub-Saharan Africa found a higher proportion of fully vaccinated children (55\% in informal settlements in Nairobi, Kenya in 2014. and 44\% in Benin City, Nigeria in 2005) [19,22].

Our finding that coverage of all routine vaccinations was similar between children in slums and non-slums was surprising. Populations within urban areas move between and within localities, and often create informal settlements, which results in heterogeneity of the population [12]. These informal settlements and slum communities within urban areas typically have gaps and inequities in the uptake of health services, particularly for childhood vaccinations. To our knowledge, this is the first time that differences in vaccination coverage have been examined between slum and non-slums within an urban setting in any African country, and although we did not identify differences in coverage, it is important to continue to assess these areas because of varying contexts and country-specific factors.

Caregivers in slums and non-slums had similar experiences, attitudes, and perceptions towards childhood vaccinations. More than one-third of all caregivers delayed vaccination for their child and thought that the time it took to reach their usual vaccination site was too long. While most caregivers believed that vaccines were safe and provided protection against diseases, approximately one quarter or more reported that parents and trusted leaders in their community were not likely to approve of childhood vaccinations and that the caregivers would not be likely to encourage other caregivers to get their child vaccinated. Further qualitative research could help shed light on how to improve confidence among caregivers to get their children vaccinated and to increase support for routine vaccination among members in the community.

To improve vaccination coverage in this urban setting of Sierra Leone, it is imperative to not only engage and educate mothers and fathers but all household members and community members in dialog, through communication channels that caregivers reported preferring (household visits, radio programming, and community-based events, in addition to health facilities). Consideration should also be given to the unique or more common media options that exist in this urban setting for sharing immunization information. Education about childhood vaccination should include why vaccines are important, how they protect against severe diseases, and risk communication about adverse events following immunization [23]. Because MCV2 coverage is so low, special attention should be brought to the importance of measles vaccination through preferred communication channels to avoid a large scale measles outbreak. Moreover, trusted local leaders (formal and informal) should be identified within diverse urban social networks and be engaged to support and role-model positive vaccination attitudes and behaviors in the community. Health facilities could consider strengthening ties with local places of worship, particularly with mosques, to reinforce vaccination messaging and provide vaccination reminders after prayer services. All communication and education messages regarding routine immunization should be developed using simple language and tested to ensure caregivers with varying degrees of education understand. 
Vaccination coverage could be further improved by ensuring routine immunization services are free of charge, increasing the number of vaccination days, modifying hours, and exploring different types of outreach activities to ensure caregivers have flexibility as to when and where they bring their child for vaccination. The majority of caregivers reported that maternal occupation was "petty trader". Thus, the market place as the most common location for petty trading should be targeted for vaccination outreach activities and demand promotion.

Educating health care workers to open vials, even if it is likely to result in some wastage could also improve coverage and enhance the relationship between the caregiver and health provider. A national policy of opening vials despite wastage and ensuring a steady supply of vaccines are needed to support this kind of health care worker education and reduce missed opportunities for vaccination [24,25]. Furthermore, more than one-third of caregivers reported delayed vaccination and delaying was associated with not getting vaccinated. In addition to encouraging health care workers to open vials when a caregiver brings a child for a vaccination session, strengthening defaulter tracking, and utilizing local community health volunteers to do so, may help to ensure that caregivers return at a later date with their child. Clear and positive communication between the provider and caregiver during vaccination sessions is also essential to ensure that the provider has fully addressed any vaccine barriers or hesitancy, such as vaccine side effects $[26,27]$.

\section{Limitations}

There were certain limitations to this study. EA maps, provided by Statistics Sierra Leone, lacked sufficient attributes to accurately identify boundaries and structures. Thus, some households may have been included or excluded inaccurately from an EA during listing. Steps were taken to mitigate inaccurate inclusion/exclusion during listing by collaborating with the cartography unit of Statistics Sierra Leone to conduct detailed sketch mapping of each EA before listing. The gap in time between enumeration and the household survey may have increased our non-response rate due to the mobility of households out of and between EAs during that time period. Additionally, although slum and nonslum status were defined by the United Nations Development Program, status of certain areas may have changed since the designation, resulting in misclassification. This study was not powered to examine vaccination coverage by birth cohort and thus we were unable to discern whether factors associated with low vaccination coverage differed by year and comparison to the 2017 MICS data should be done so with caution. Lastly, almost one quarter $(24 \%)$ of caregivers did not have their child's vaccination card available. This may have introduced bias because the analysis of factors associated with coverage only included children with vaccination cards.

\section{CONCLUSIONS}

Findings from this survey highlight barriers faced by caregivers to access and utilize childhood immunization services in slum and non-slums in WAU, Sierra Leone. As a next step, the Sierra Leone MoHS and global health partners will collaborate on implementing key interventions to address identified challenges to childhood vaccination in WAU.

Acknowledgements: We would like to thank the following data collectors for their contributions to the survey: Dennis Royce Bundu, Edwina, Emmanuel Bernard, Felix Kanu, Gibrilla James Kamara, Hamid Lansama Kai, Isata Janet Kamara, Isha Bawoh, James Brinsley Palmer, James Ngebeh, Jerikatu Lansana, Kadiatu Nabay, Kemoh Fomba Lawleh, Massah Mary Kanu, Melvin Paul, Mohamed Feika, Mohamed Sansusi Koroma, Musa Saffea Koroma, Priscillia Bondu Sani, Samilia Kamara, Steven Saidu, Unisa Abubakarr Jalloh, Victoria Dixie-Luke, Zainab Sankoh.

Funding: None declared.

Author contributions: Conceptualization and methodology: LF, RS, MJ, AW, LC, SK, MLS, TS, OE Data curation: LF, RS, LP, MJ, Data collection: LF, LP, RS, AM, OE, AA, Formal analysis: LF, LP, SK, Writing: LF, MJ, AW, SK, Final approval: LF, RS, MJ, LC, AW, SK, MLS, TS OE, AA, AM, and SK.

Competing interest: The authors completed the ICMJE Unified Competing Interest form (available upon request from the corresponding author) and declare no conflicts of interest.

\section{Additional material}

Online Supplementary Document 
1 Jean Paul Uwizihiwe HB. 40th anniversary of introduction of Expanded Immunization Program (EPI): A literature review of introduction of new vaccines for routine childhood immunization in sub-Saharan Africa. International Journal of Vaccines and Vaccination. 2015;1. doi:10.15406/ijvv.2015.01.00004.

2 Expanded programme on immunization. Programme review. Wkly Epidemiol Rec. 1994;69:87-90. Medline:8003403

3 World Health Organization. Immunization, Vaccines and Biologicals: Estimates of disease burden and cost-effectiveness. Available: https://www.who.int/immunization/monitoring_surveillance/burden/estimates/en/. Accessed:

4 April 2019. 4 World Health Organization. Progress and Challenges with Achieving Universal Immunization Coverage. Geneva, Switzerland: 2017.

5 Sanitation GoSLMoHa. Comprehensive EPI multi-year plan: 2012-2016. 2014. Available: https://extranet.who.int/countryplanningcycles/sites/default/files/country_docs/Sierra\%20Leone/cmyp-_2012-2016_narrative_for_sierra_leone_final_ updated_on_the_23_jan_2014.pdf. Accessed 5 April 2019.

6 World Health Organization. Analytical summary - Immunization and vaccines development - Sierra Leone. Available: http://www.aho.afro.who.int/profiles_information/index.php/Sierra_Leone:Analytical_summary_-_Immunization_and_ vaccines_development. Accessed: 4 April 2019.

7 World Health Organization and UNICEF. Sierra Leone: Estimates of immunization coverage: 2017 revision. Available: http://apps.who.int/immunization_monitoring/globalsummary/estimates?c=SLE. Accessed: 4 April 2019.

8 World Health Organization. Measles outbreak confirmed in northern Sierra Leone. Available: https://afro.who.int/news/ measles-outbreak-confirmed-northern-sierra-leone. Accessed: 4 April 2019.

9 Statistics Sierra Leone. 2015 Population and Housing Census, summary of final results. Freetown, Sierra Leone: 2015.

10 Crocker-Buque T, Mindra G, Duncan R, Mounier-Jack S. Immunization, urbanization and slums - a systematic review of factors and interventions. BMC Public Health. 2017;17:556. Medline:28595624 doi:10.1186/s12889-017-4473-7

11 Statistics Sierra Leone - SSL. Sierra Leone Multiple Indicator Cluster Survey, 2017, Survey Findings Report Freetown, Sierra Leone: Statistics Sierra Leone, 2018.

12 Nelson KN, Wallace AS, Sodha SV, Daniels D, Dietz V. Assessing strategies for increasing urban routine immunization coverage of childhood vaccines in low and middle-income countries: A systematic review of peer-reviewed literature. Vaccine. 2016;34:5495-503. Medline:27692772 doi:10.1016/j.vaccine.2016.09.038

13 UNICEF. Advantage or Paradox? The challenge for children and young people of growing up urban. 2018.

14 The United Nations Development Programme and The Government of Sierra Leone. The Improvement of Slums and Informal Settlements in Freetown. 2006.

15 World Health Organization. Immunization coverage cluster survey-Reference manual Available: http://apps.who.int/ iris/bitstream/10665/69087/1/WHO_IVB_04.23.pdf. Accessed: 20 September 2019.

16 Landoh DE, Ouro-Kavalah F, Yaya I, Kahn A-L, Wasswa P, Lacle A, et al. Predictors of incomplete immunization coverage among one to five years old children in Togo. BMC Public Health. 2016;16:968. Medline:27618851 doi:10.1186/ s12889-016-3625-5

17 Douba A, Aka LBN, Yao GHA, Zengbé-Acray P, Akani Bangaman C, Konan NG. Facteurs sociodémographiques associés à la vaccination incomplète des enfants de 12 à 59 mois dans six pays d'Afrique de l'ouest. [in French]. Sante Publique. 2015;27:723-32. Medline:26752038 doi:10.3917/spub.155.0723

18 Ndiaye NM, Ndiaye P, Diedhiou A, Gueye AS, Tal-Dia A. Factors related to failure to complete immunization of children aged 10-23 months in Ndoulo (Senegal. Sante. 2009;19:9-13. Medline:19801345

19 Mutua MK, Kimani-Murage E, Ettarh RR. Childhood vaccination in informal urban settlements in Nairobi, Kenya: who gets vaccinated? BMC Public Health. 2011;11:6. Medline:21205306 doi:10.1186/1471-2458-11-6

20 Tadesse H, Deribew A, Woldie M. Predictors of defaulting from completion of child immunization in south Ethiopia, May 2008: a case control study. BMC Public Health. 2009;9:150. Medline:19463164 doi:10.1186/1471-2458-9-150

21 Russo G, Miglietta A, Pezzotti P, Biguioh RM, Bouting Mayaka G, Sobze MS, et al. Vaccine coverage and determinants of incomplete vaccination in children aged 12-23 months in Dschang, West Region, Cameroon: a cross-sectional survey during a polio outbreak. BMC Public Health. 2015;15:630. Medline:26156158 doi:10.1186/s12889-015-2000-2

22 Sadoh AE, Eregie CO. Timeliness and completion rate of immunization among Nigerian children attending a clinic-based immunization service. J Health Popul Nutr. 2009;27:391-5. Medline:19507754 doi:10.3329/jhpn.v27i3.3381

23 World Health Organization. Immunization in practice: a practical guide for health staff - 2015 update. Geneva, Switzerland: WHO; 2015

24 Wallace AS, Willis F, Nwaze E, Dieng B, Sipilanyambe N, Daniels D, et al. Vaccine wastage in Nigeria: An assessment of wastage rates and related vaccinator knowledge, attitudes and practices. Vaccine. 2017;35 48 Pt B:6751-8. Medline:29066189 doi:10.1016/j.vaccine.2017.09.082

25 Wallace AS, Krey K, Hustedt J, Burnett E, Choun N, Daniels D, et al. Assessment of vaccine wastage rates, missed opportunities, and related knowledge, attitudes and practices during introduction of a second dose of measles-containing vaccine into Cambodia's national immunization program. Vaccine. 2018;36:4517-24. Medline:29907485 doi:10.1016/j. vaccine.2018.06.009

26 Oku A, Oyo-Ita A, Glenton C, Fretheim A, Ames H, Muloliwa A, et al. Perceptions and experiences of childhood vaccination communication strategies among caregivers and health workers in Nigeria: A qualitative study. PLoS One. 2017;12:e0186733. Medline:29117207 doi:10.1371/journal.pone.0186733

27 Ames HMR, Glenton C, Lewin S. Parents' and informal caregivers' views and experiences of communication about routine childhood vaccination: a synthesis of qualitative evidence. Cochrane Database Syst Rev. 2017;2:CD011787. Medline:28169420 doi:10.1002/14651858.CD011787.pub2 